\title{
Optimal SOC Reference Based Active Cell Balancing on a Common Energy Bus of Battery
}

\author{
SunHo Bae*, Jung-Wook Park* and Soo Hyoung Lee ${ }^{\dagger}$
}

\begin{abstract}
This paper presents a study on the state-of-charge (SOC) reference based active cell balancing in real-time. The optimal references of SOC are determined by using the proposed active cell balancing system with the bidirectional DC/DC converters via the dual active bridge (DAB) type. Then, the energies between cells can be balanced by the power flow control of DAB based bidirectional DC/DC converters. That is, it provides the effective management of battery by transferring energy from the strong cell to the weak one until the cell voltages are equalized to the same level and therefore improving the additional charging capacity of battery. In particular, the cell aging of battery and power loss caused from energy transfer are considered. The performances of proposed active cell balancing system are evaluated by an electromagnetic transient program (EMTP) simulation. Then, the experimental prototype is implemented in hardware to verify the usefulness of proposed system.
\end{abstract}

Keywords: Active cell balancing, Bidirectional DC/DC converter, Dual active bridge converter, Lithium-ion battery, State-of-charge

\section{Introduction}

The lithium-ion battery is the one of most popular energy storage devices because of its advantageous properties. That is, it has the nonmemory effect, high-working cell voltage, high power and energy density, and low environmental pollution, etc [1]. Therefore, it has been widely being used in many practical applications such as portable electrical appliances, electric vehicles, communication devices, and even distributed generations (DGs) in power system, etc $[2,3]$.

Since the voltage of single cell is inherently low, a battery pack requires a large number of cells connected in series to achieve a higher terminal voltage and output capacity. However, the cell voltage imbalance within a series string can occur by the difference of cell internal resistances, imbalanced state-of-charge (SOC) between cells, degradation of each cell, and temperature gradients of battery pack, etc $[1,4-6]$. In particular, its repeated charging and discharging operation aggravates the cell voltage imbalance, and this finally can cause to decrease in the total storage capacity and battery lifetime.

To figure out this problem, many cell balancing methods $[7,8]$ have been proposed so far. In general, these can be categorized into two representative methods, which are the passive and active balancing methods. The passive balancing method [9-11] removes excess energy from stronger cells by shunting a resistor across each cell until

$\dagger$ Corresponding Author: Korea Electrotechnology Research Institute (KERI), Korea. (slee82@keri.re.kr)

* School of Electrical and Electronic Engineering, Yonsei University,

Korea. (\{bsunho,jungpark@yonsei.ac.kr)

Received: March 24, 2016; Accepted: July 26, 2016 the shunted cells reach to the voltage of the weakest cell. This method is simple to implement for the cell balancing in a battery pack. However, it causes the energy dissipating problem in the applied resistors. Therefore, it not only results in thermal control difficulty of pack, but also decreases efficiency of battery system. These problems can be overcome by the active balancing method, which uses active switching circuits to transfer excess energy from stronger cells to weaker cells, and therefore reduces energy loss effectively. There is a disadvantage that cost will increase because the active balancing system needs more power devices. However, it can improve the performance and lifespan of battery pack [12]. Meanwhile, the power electronic circuit in the active balancing method is implemented based on the unidirectional $[13,14]$ or bidirectional approach. Then, two representative topologies, which are the flyback $[15,16]$ and the buck-boost [17-19] converters, have been used for the bidirectional approach.

In general, the active balancing method defines its objective function with two balancing criteria, which are voltage and SOC of battery. When the voltage is used, it equalizes the terminal voltage of each cell during balancing operation. Therefore, this is only effective in low and high SOC regions because its open- circuit voltage is almost flat in moderate SOC region. Moreover, this method does not ensure the balanced SOC if the capacity of cells is different. In contrast, when the SOC is used [20-23], the usable energy of battery pack can be improved, and more accurate cell balancing can be achieved in moderate SOC region. This is because whether to charge or discharge a cell is determined by comparing the SOC of each cell with its reference. 
In most cases, the average SOC of all cells has been used as the reference for individual SOC balancing control. However, it is not possible to set the correct balancing reference without considering the cell aging and power loss caused during energy transfer. The incorrect reference causes many problems. It requires more time for cell balancing and the conversion loss caused from bidirectional $\mathrm{DC} / \mathrm{DC}$ converter is increased during the operation. Most of all, the battery lifetime is reduced by more charge or discharge operation.

To solve this problem, this paper makes the new contribution by selecting the reference of SOC optimally based on the common energy bus and therefore improving the energy efficiency and lifespan of battery more effectively.

This paper is organized as follows: Section 2 shows the proposed active cell balancing system with its structure and explains how to determine the optimal reference of SOC while considering the cell aging and energy transfer efficiency. Then, Section 3 describes the topology, operation, and control scheme of DAB based bidirectional DC/DC converters to implement the proposed system. Thereafter, the performances and usefulness of proposed system in real-time are evaluated and verified by both the electromagnetic transient program (EMTP) based simulation and experimental tests in Sections 4 and 5, respectively. Finally, conclusions are given in Section 6.

\section{The Proposed Active Cell Balancing System}

\subsection{Structure of proposed modeling}

The system structure of proposed active cell balancing system is shown in Fig. 1. It consists of a battery pack with several series-connected battery cells, bidirectional DC/DC converters, and the common energy bus by single capacitor. Note that the bidirectional DC/DC converters are connected in parallel with each cell, and they are connected to the common energy bus.

The proposed cell balancing system operates to transfer the excess energy of stronger cells to the common energy

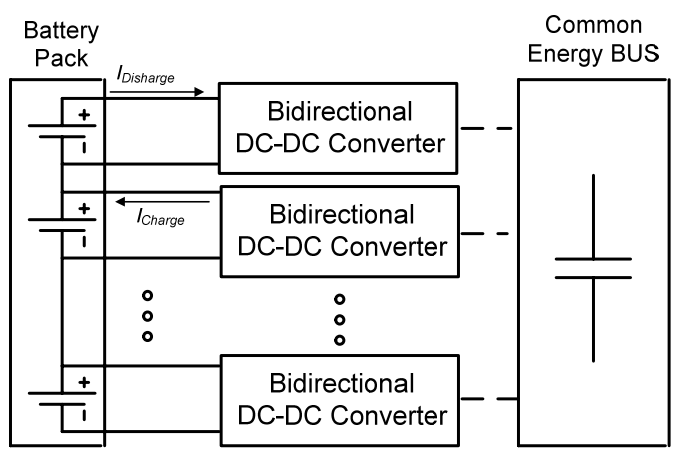

Fig. 1. Structure of the proposed active cell balancing system bus, which also delivers that energy to weaker cells via the bidirectional DC/DC converters. It is important to note that they play the important role of controlling the power flow between each cell and the common energy bus. For stronger cells, they operate in a discharging mode. In other words, the power flows from the cell to the energy bus. As the result, the cell is discharged, and the capacitor of common energy bus is charged. In contrast, they operate in a charging mode for weaker cells. That is, the power flows from the energy bus to the cell. Then, the bus capacitor is discharged, and the cell is charged.

Even though the proposed active cell balancing system in Fig. 1 exploits the bidirectional DC/DC converters similarly to the previous applications, there is the distinct difference. In other words, the bidirectional DC/DC converters based approaches in previous studies have performed the function of cell-to-cell and cell-to-string balancing with the buck-boost and the flyback topologies, respectively. They require the long balancing time, especially when the strongest and weakest cells are separated far apart in a battery pack. In contrast, the proposed system can reduce the balancing time dramatically because even if stronger and weaker cells are in any positions in the battery pack, it can be balanced at the same time with a common energy bus, to which all cells are connected.

\subsection{Determination of optimal reference SOC}

In general, the battery cell ages due to its internal resistances and higher terminal voltages, and this degrades the usable battery capacity [24] even though all cells in a new battery pack show the same characteristics and aging initially. Moreover, the difference between SOC of cells accelerates the aging process of battery while resulting in the different maximum capacity of cell.

To reduce this harmful effect, the average SOC method can be used. In other words, the SOC reference of each cell is selected as the average value of SOC of all cells. An example of balancing SOC of three cells with the average SOC method is illustrated in Fig. 2. Before cell balancing, cells 1 to 3 are aged with the capacity of 80,90 , and $100 \%$, respectively. And, their SOCs are 80, 65, and $60 \%$, respectively. Based on the average SOC method, the reference of SOC becomes $68.3 \%$, and this is applied to three cells. Firstly, for cell 1, the difference between its initial SOC and the reference is $11.7 \%$. Then, by the cell balancing operation, the transferred energies from cell 1 to cells 2 and 3 are $2.93 \%$ and $2.63 \%$, respectively, considering the capacities and the converter efficiency of $80 \%$. After cell balancing, the SOC reference determined by the average SOC method is $66.29 \%$, as shown in Fig. 2(b). There is still small difference between the SOCs of all cells and its reference. In other words, the same process must be iteratively applied until their all SOCs are adjusted to its reference correctly. Note that the difference between 

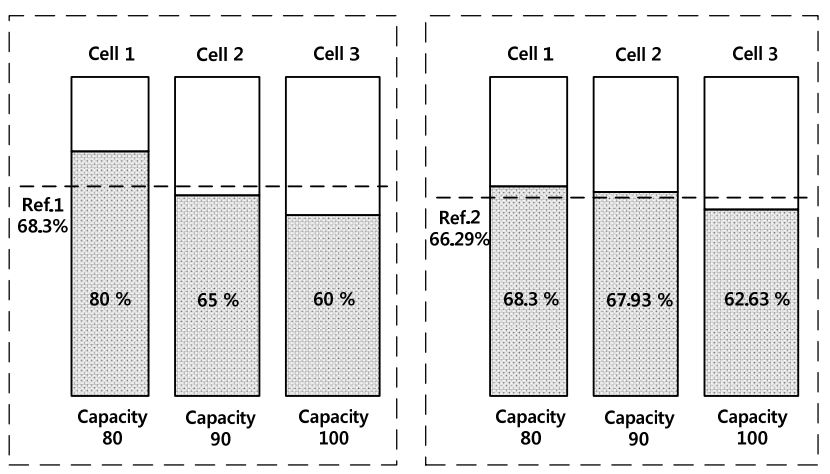

Fig. 2. Example of balancing SOC of three cells with the average SOC method: (a) Before cell balancing; (b) After cell balancing

Table 1. Parameters of battery cells

\begin{tabular}{cc}
\hline Parameters & Description \\
\hline$C_{1}, C_{2}, C_{n}$ & Maximum capacity of cells \\
$\mathrm{SOC}_{1}, \mathrm{SOC}_{2}, \mathrm{SOC}_{n}$ & Initial SOC of each cell \\
$\mathrm{SOC}_{r e f}$ & Reference of SOC \\
$E_{\text {sum }}$ & Sum of energies in all cells \\
$E_{T}$ & Transferred energy \\
$\eta$ & Efficiency of energy transfer \\
\hline
\end{tabular}

the energy capacities of cells due to their aging causes this error. Moreover, this is aggravated when the conversion loss caused from bidirectional DC/DC converter is increased during energy transfer. To solve this problem, this study proposes the new method to select the optimal reference of SOC as follows.

The parameters associated with battery cells are defined in Table 1. The initial SOC and capacity condition of cells are assumed to be the same as those of example in Fig. 2. Firstly, the total amount of energies in all cells, $E_{\text {sum }}$ is calculated as

$$
E_{\text {sum }}=\mathrm{SOC}_{1} \cdot C_{1}+\mathrm{SOC}_{2} \cdot C_{2}+\cdots+\mathrm{SOC}_{n} \cdot C_{n}
$$

When the SOC reference, $\mathrm{SOC}_{r e f}$ is considered, the $E_{\text {sum }}$ in (1) can be also computed as

$$
E_{\text {sum }}=\left(C_{1}+C_{2}+\cdots+C_{n}\right) \cdot \mathrm{SOC}_{r e f}
$$

By (1) and (2), the $\mathrm{SOC}_{r e f}$ is finally determined as

$$
\mathrm{SOC}_{r e f}=\frac{\mathrm{SOC}_{1} \cdot C_{1}+\mathrm{SOC}_{2} \cdot C_{2}+\cdots+\mathrm{SOC}_{n} \cdot C_{n}}{C_{1}+C_{2}+\cdots+C_{n}}
$$

In the example of Fig. 2(a), the value of initial $\mathrm{SOC}_{\text {ref }}$ by (3) is $67.59 \%$, and it is more accurate than that by using the average SOC method. However, the energy required for some cells to reach their $\mathrm{SOC}_{r e f}$ might be insufficient even after cell balancing because the power conversion loss during energy transfer is not considered in this case. To consider this, the transferred energy, $E_{T}$ is estimated as

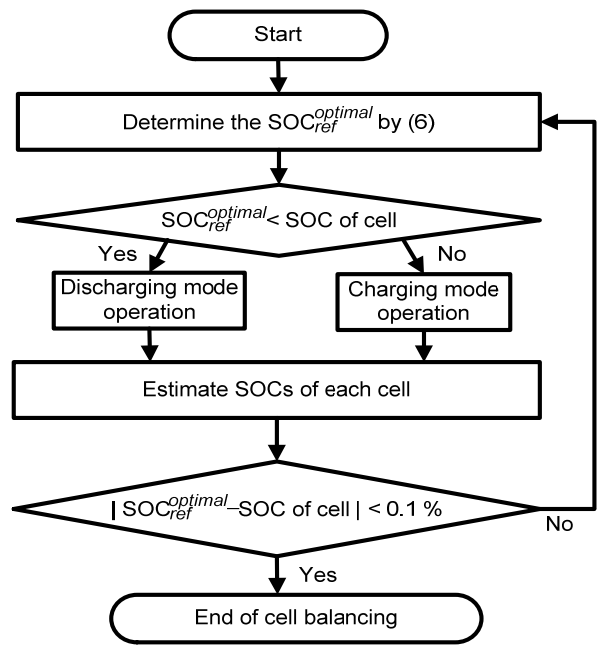

Fig. 3. Flow chart to implement the proposed active cell balancing system with the optimal reference of SOC

$$
E_{T}=\sum_{i=1}^{n}\left|\mathrm{SOC}_{i}-\mathrm{SOC}_{r e f}\right| \cdot C_{i}
$$

Then, the $E_{\text {sum }}$ in (2) is modified as (5) with the $E_{T}$ in (4) and its efficiency, $\eta$, and the optimal SOC reference, is represented as (6).

$$
\begin{aligned}
& E_{\text {sum }}=E_{T} \cdot(1-\eta)+\left(C_{1}+C_{2}+\cdots+C_{n}\right) \cdot \mathrm{SOC}_{\text {ref }}^{\text {optimal }} \\
& \mathrm{SOC}_{\text {ref }}^{\text {optimal }}=\frac{\left(\mathrm{SOC}_{1} \cdot C_{1}+\mathrm{SOC}_{2} \cdot C_{2}+\cdots+\mathrm{SOC}_{n} \cdot C_{n}\right)-E_{T} \cdot(1-\eta)}{C_{1}+C_{2}+\cdots+C_{n}}
\end{aligned}
$$

Fig. 3 shows the flow chart to implement the proposed active cell balancing system with the $\mathrm{SOC}_{\text {ref }}^{\text {optimal }}$, by (6). If the SOC of a cell is greater than the $\mathrm{SOC}_{\text {ref }}^{\text {optimal }}$, the proposed $\mathrm{DAB}$ based bidirectional $\mathrm{DC} / \mathrm{DC}$ converter operates in a boost mode to discharge the cell. Otherwise, it operates in a buck mode to charge the cell. Then, all SOCs of cells are estimated and compared with the $\mathrm{SOC}_{\text {ref }}^{\text {optimal }}$. When the absolute difference between the $\mathrm{SOC}_{\text {ref }}^{\text {optimal }}$ and the changed SOC of cell is less than $0.1 \%$, the proposed cell balancing is successfully completed. In other words, all cells are considered to match the $\mathrm{SOC}_{\text {ref }}^{\text {optimal }}$ while having the almost same SOC between them. Therefore, this can improve the performance and lifespan of battery effectively by considering its cell aging and power loss caused during energy transfer.

\section{Dual Active Bridge Based Bidirectional DC/DC Converter}

\subsection{Topology and operation}

In implementation of proposed active cell balancing system, the isolated bidirectional DC/DC converter is 


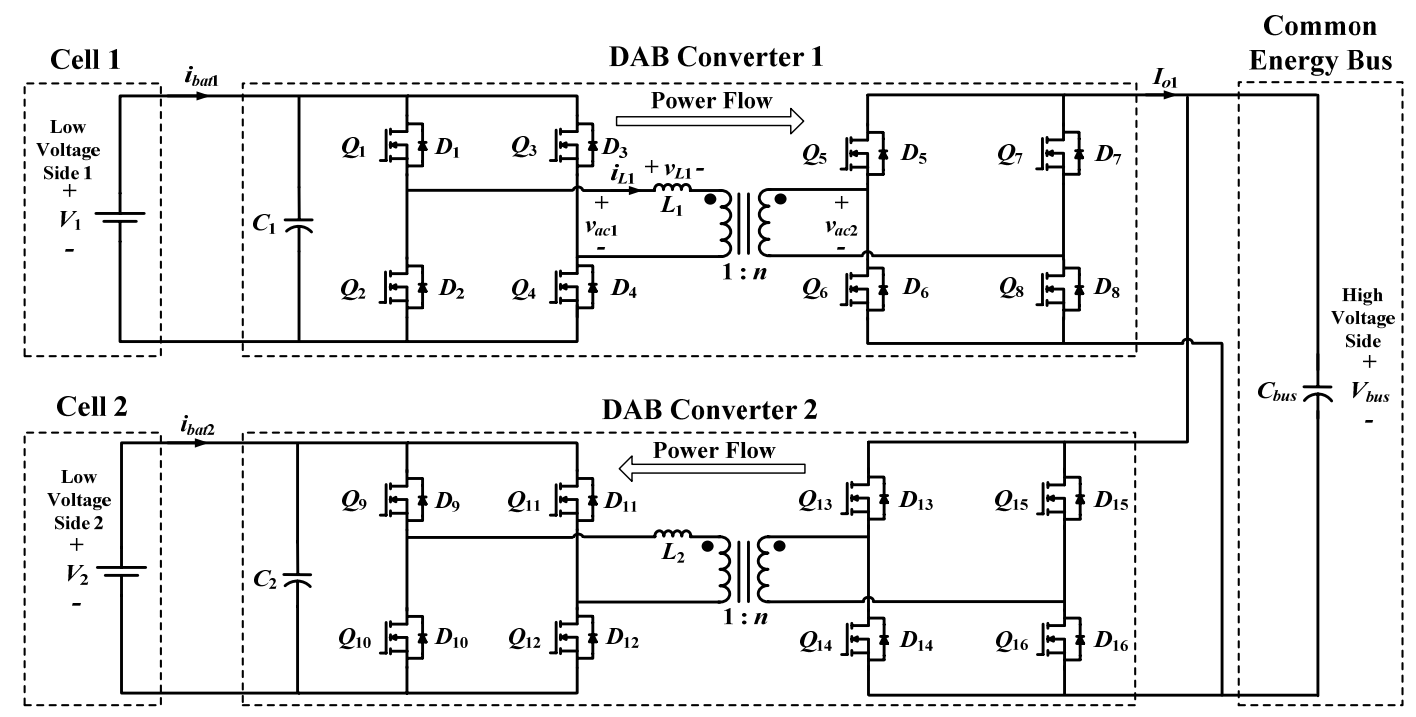

Fig. 4. Overall system structure with two DAB converters

required. In the battery pack, as shown in Fig. 1, all cells are connected in series for high output voltage. But at the same time, all cells are connected to the common energy bus capacitor in parallel through the $\mathrm{DC} / \mathrm{DC}$ converter. If the non-isolated type is used, then cathodes and anodes of all cells might be short. In addition, unlike the low voltage side of each cell, the voltage level in common energy bus must be large enough for charging mode operation. This means that the high voltage ratio of input and output must be available.

As mentioned previously, the DAB based bidirectional $\mathrm{DC} / \mathrm{DC}$ converter is applied in this study. It provides galvanic isolation, a high voltage ratio, and bidirectional power-flow capability. In particular, the popularity of DAB type is growing because of its many advantages such as low stress on device and components, small size of filter, effective bidirectional power-flow capability, and easy soft-switching implementation, etc [25-28]. The switching function, voltage, and current waveforms in a discharging mode of single DAB based bidirectional DC/DC converter are shown in Fig. 4. And, the overall system structure with two converters is given in Fig. 4. Each converter has two H-bridge types in both sides. They are connected by the high -frequency isolation transformer and the inductor, $L$.

In general, there are two modulation methods for the control of DAB converter. The first method is the pulsewidth-modulation (PWM). In PWM, the switch pairs, $\left(Q_{l}\right.$, $\left.Q_{4}\right)$ and $\left(Q_{2}, Q_{3}\right)$ in primary H-bridge and the switch pairs $\left(Q_{5}, Q_{8}\right)$ and $\left(Q_{6}, Q_{7}\right)$ in secondary H-bridge are switched in turn. The currents flow through the freewheeling diode, $D_{1}$ to $D_{8}$. Then, the power is transferred from $V_{1}$ to $V_{b u s}$, as shown in Fig. 4. To operate the reverse power flow, the switching states of above pairs in primary and secondary H-bridges are exchanged. This method is simple and easy to implement, but its dynamic performance is poor.

The second method is the phase-shift modulation. The

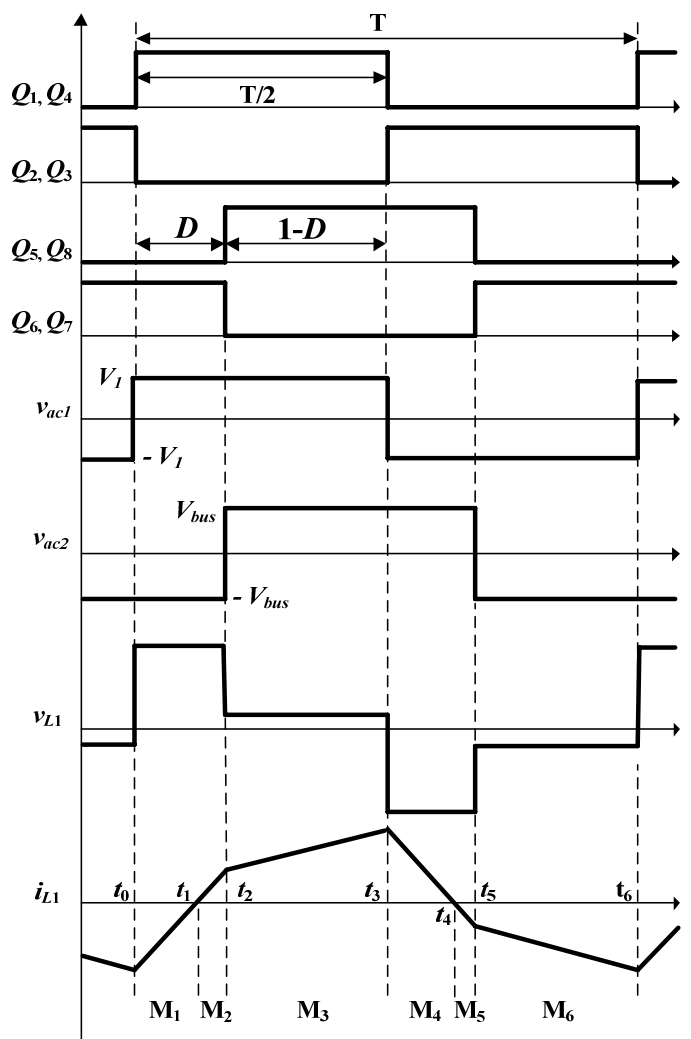

Fig. 5. Waveforms of DAB converter in a discharge mode

cross-connected switch pairs in both H-bridges have $50 \%$ duty cycle. And, they are switched in turn to generate the phase-shifted square waveforms, $v_{a c 1}$ and $v_{a c 2}$ in Fig. 5. These change the voltage across the inductor, $v_{L 1}$. This makes it possible to manipulate the direction and magnitude of the power flow. Moreover, this modulation method can provide the effective dynamic performance and easy softswitching implementation. Thus, the phase-shift modulation is applied in this study. 
The more details and associated equations of DAB converter are given in [26]. For simplicity, the $V_{1}$ and $V_{\text {bus }}$ are assumed to be constant over one switching period, $\mathrm{T}$. Then, the average discharge battery power can be calculated as

$$
P_{o 1}=\frac{V_{1} V_{b u s} D(1-D)}{2 n f_{s} L_{1}}
$$

where $D$ is the phase-shift delay. When the gate signal in primary H-bridge leads that in secondary H-bridge, the value of $D$ is in the range from 0 to $1(D \in[0,1])$. Then, the $P_{o 1}$ is positive, and the converter operates in the discharge mode. In contrast, when the primary gate signal lags the secondary gate signal, the value of $D$ is in the range from -1 to $0(D \in[-1,0])$, and the $P_{o 1}$ is negative. In this charging mode, the power flows from the energy bus to the battery cell.

\subsection{Control scheme}

The control block diagram of DAB converter by using the phase-shift modulation is shown in Fig. 6. The battery current, $i_{b a t}$ is firstly measured, and it is injected as the input. Then, the error between the $i_{b a t}$ and the reference current, $i_{\text {ref }}$ goes to the proportional-integral (PI) controller. Note that the output of PI controller must be limited to meet the range of phase-shift delay, $D$.

In Fig. 6, the original carrier signal is used to create the PWM signals of $Q_{1}$ and $Q_{4}$. Because the switch pairs of $\left(Q_{1}\right.$ and $\left.Q_{4}\right)$ and $\left(Q_{2}\right.$ and $\left.Q_{3}\right)$ are switched in turn, the inversed square waveforms to switches, $Q_{1}$ and $Q_{4}$ are injected to the switches, $Q_{2}$ and $Q_{3}$. To create the proper switching signals in secondary H-bridge, the delayed carrier signal is generated by the sum of original carrier signal and phaseshift delay, $D$. Then, it is used to make the delayed PWM signals of $Q_{5}$ and $Q_{8}$. Similarly to the primary H-bridge, their inversed square waveforms become the PWM

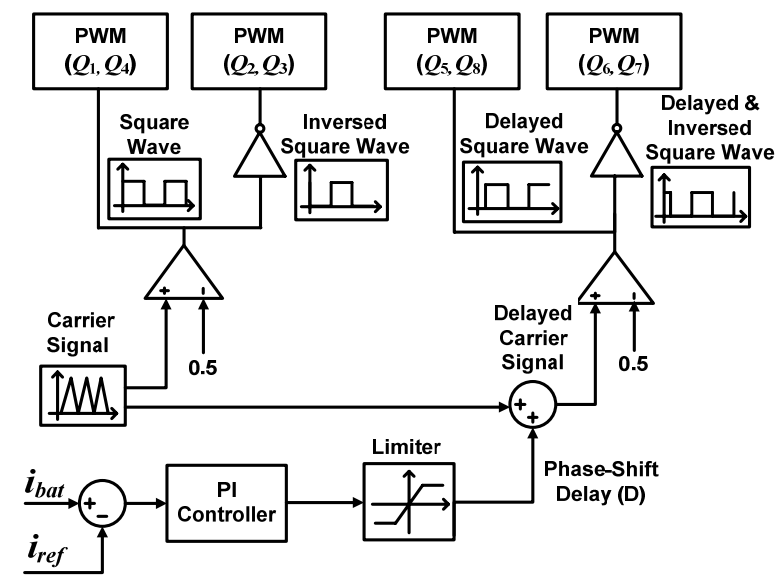

Fig. 6. Control block diagram of DAB converter by using the phase-shift modulation signals of $Q_{6}$ and $Q_{7}$. As in [28], the analytical equations of output current, $I_{o 1}$ flowing through the inductor and output voltage, $V_{\text {bus }}$ in secondary H-bridge are given as (8) and (9), respectively. Note that they can be controlled by manipulating the value of $D$.

$$
\begin{aligned}
I_{o 1} & =\frac{V_{1}}{2 f_{s} L_{1}} D(1-D) \\
V_{\text {bus }} & =\frac{V_{1}}{2 f_{s} L_{1}} D(1-D) R
\end{aligned}
$$

When the $\mathrm{SOC}_{\text {ref }}^{\text {optimal }}$ in (6) is set, all converters are controlled for the cell balancing operation. Firstly, each converter on a discharging mode is individually controlled through the current control, as shown in Fig. 6. Then, all converters in a charging mode are controlled at the same time to maintain the common bus voltage, $V_{\text {bus }}$. However, it is required to set the reasonable $i_{\text {ref }}$ because of the different number of converters in charging and discharging modes. For example, when the number of discharging cells is more than that of charging cells, and the $i_{r e f}$ is set too high, the common bus voltage increases due to the maximum current limit of converters in charging mode. In contrast, if the $i_{\text {ref }}$ is set too low, it will take long time for the balancing operation. Therefore, when the number of discharging cells is less than that of charging cells, the $i_{\text {ref }}$ is set to a maximum converter current, $i_{\max }$. Otherwise, the $i_{\text {ref }}$ is determined as

$$
i_{\text {ref }}=i_{\max } \frac{N_{\text {charging mode }}}{N_{\text {discharging mode }}}
$$

where $N_{\text {charging mode }}$ and $N_{\text {discharging mode }}$ are the number of converter in charging and discharging modes, respectively.

\section{Simulation Results}

The performance of proposed active cell balancing system is evaluated by time-domain simulation with the power systems computer aided design/electromagnetic transients including DC (PSCAD/EMTDC®) software. Firstly, the characteristics of cells are modeled by using the equivalent electric circuit of battery [29, 30]. In other words, its open circuit voltage (OCV) is simulated by a DC voltage source. The values of resistors and capacitors are determined by considering the electrochemical characteristics of battery. Then, the SOC of cell is calculated by the using ampere-hour counting method as (11).

$$
\mathrm{SOC}=\mathrm{SOC}_{\text {initial }}+\frac{\int i \cdot d t}{\text { Capacity }}
$$

Thereafter, the OCV is estimated by using the SOC- 
Table 2. Parameters of proposed active cell balancing system

\begin{tabular}{cc}
\hline Parameters & Value \\
\hline Cell voltages $\left(V_{1}, V_{2}\right)$ & $3.3-4.1 \mathrm{~V}$ \\
DC capacitors $\left(C_{1}, C_{2}, C_{\text {bus }}\right)$ & $1000 \mu \mathrm{F}$ \\
Transformer turns ratio $(n)$ & 10 \\
Inductances $\left(L_{1}, L_{2}\right)$ & $200 \mu \mathrm{H}$ \\
Switching frequency $\left(f_{s}\right)$ & $50 \mathrm{kHz}$ \\
Energy bus capacitor voltage $\left(V_{\text {bus }}\right)$ & $0-50 \mathrm{~V}$ \\
Output power $\left(P_{o}\right)$ & $0-10 \mathrm{~W}$ \\
\hline
\end{tabular}

OCV curve. More details are described in [29] and [30].

The parameters of proposed active cell balancing system in Fig. 4 are listed in Table 2. The initial SOC of aged cell 1 in low-voltage side 1 is 0.8 , and its maximum capacity is $1 \mathrm{Ah}$. The initial SOC of fresh cell 2 in low-voltage side 2 is 0.5 , and its maximum capacity is 1.25 . In high-voltage side of Fig. 5, the cathode and anode of bus capacitor are connected to the secondary H-bridge of both DAB converters. Then, the DAB converter 1 initially operates in a discharging mode, where the power flows from low- to high-voltage side. In contrast, the DAB converter 2 operates in a charging mode, and therefore the direction of power flow is reversed.

There are two phase-shift delays available for two DAB converters 1 and 2, which are $D_{1}$ and $D_{2}$ to control cells 1 and 2 , respectively. For example, when the $i_{b a t 2}$ is controlled, $D_{2}$ is used to respond the system while $D_{1}$ is fixed. Then, since the DAB converter has the maximum efficiency at $D$ of $0.05 \mathrm{~T}$, D1 is fixed with $0.05 \mathrm{~T}$, and $D_{2}$ is varied between $0.05 \mathrm{~T}$ and $0.10 \mathrm{~T}$. The simulation results of battery currents, $i_{\text {bat } 1}$ and $i_{\text {bat }}$, and bus voltage responses are shown in Figs. 7 and 8, respectively. The directions of $i_{\text {bat } 1}$ and $i_{\text {bat } 2}$ in Fig. 7 are opposite. This means that the cells 1 and 2 are discharged and charged, respectively. The detailed operations are described in the following three time intervals.

- Interval I ( $0 \mathrm{~s}-0.1 \mathrm{~s})$ : The discharging current, ibat1 starts to increase. Therefore, the bus voltage, $V_{b u s}$ is also increased. The DAB converter 2 starts to operate after the value of $V_{b u s}$ is greater than $15 \mathrm{~V}$. Thus, the $i_{\text {bat } 2}$ is zero until this point. After that, the $i_{b a t 1}$ and $V_{b u s}$ keep increasing. However, their rates of change are decreased. The $D_{2}$ is kept with its maximum value $0.10 \mathrm{~T}$.

- Interval II $(0.1 \mathrm{~s}-0.4 \mathrm{~s})$ : The error between the $i_{\text {bat } 2}$ and its reference of $1.3 \mathrm{~A}$ becomes very small at $0.1 \mathrm{~s}$, the $D_{2}$ is decreased so that the charging and discharging energies are almost balanced in the common energy bus. At the same time, the $i_{b a t 1}$ is decreased rapidly because the charging of the bus capacitor is completed. This results in a nearly constant $V_{\text {bus }}$.

- Interval III $(0.4 \mathrm{~s} \mathrm{-})$ : At $0.4 \mathrm{~s}$, the reference of $i_{\text {bat } 2}$ is changed from 1.3 A to 2.3 A. This causes a sudden increase of error to PI controller in Fig. 6 and the bus capacitor needs more power. Therefore, the $i_{b a t 1}$ is suddenly increased in this time. Then, $D_{2}$ is controlled to

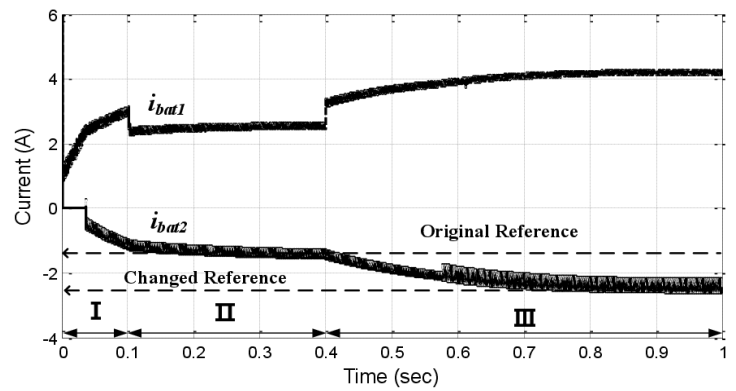

Fig. 7. Simulation results of battery current response

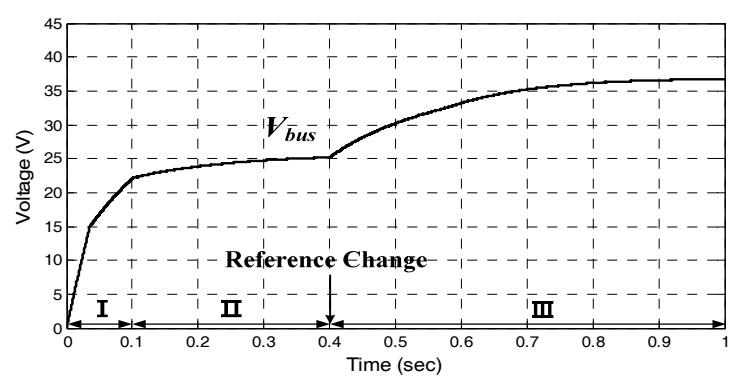

Fig. 8. Simulation results of bus voltage response

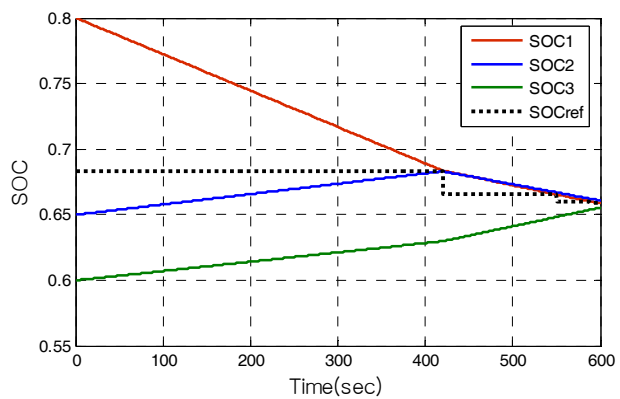

(a)

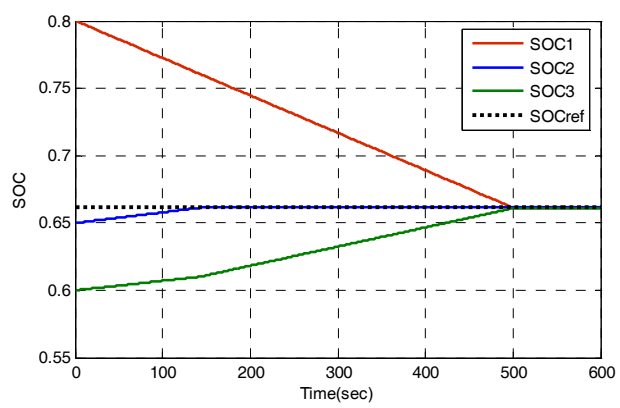

(b)

Fig. 9. Variations of SOCs of three cells in the example of Fig. 2: (a) by average SOC method, (b) by the proposed active cell balancing method

output the corresponding step increase in $i_{b a t 2}$. Thereafter, the $V_{b u s}$ and the $i_{b a t 2}$ are also increased until they reach to their new steady-state values.

Also, when the proposed optimal SOC reference, SOC $_{\text {ref }}^{\text {optimal }}$ by (6) is applied to the example of Fig. 2, the corresponding variations of SOCs of three cells are 
compared in Fig. 9 to those by the average SOC method. It is clearly observed from the results in Fig. 9(a) that three SOC references are re-calculated during the cell balancing by the average SOC method whenever any of SOCs of cells reaches to the reference. Correspondingly, all SOCs become almost same at around $600 \mathrm{~s}$.

In contrast, for the proposed active cell balancing method, the $\mathrm{SOC}_{\text {ref }}^{\text {optimal }}$ is initially determined by (6), and it is kept as the same initial value until all SOCs become almost same within around $500 \mathrm{~s}$.

\section{Experimental Results}

\subsection{Hardware implementation}

The usefulness of proposed system is verified by hardware implementation, as shown in Fig. 10. The DAB converter is implemented in power board with 8 metal oxide semiconductor field effect transistors (MOSFETs), 8 freewheeling diodes, a high-frequency transformer, and an inductor. The cell current is measured by using a hall current sensor in low-voltage side, which converts the voltage in the range from $-5 \mathrm{~V}$ to $5 \mathrm{~V}$. Then, it is scaled down within the input range from 0 to $3.3 \mathrm{~V}$ of microprocessor by the analog-to-digital converter (ADC) circuit in control board.

The scaled analog voltage is injected to the digital signal processor (DSP) of TMS320C28346. Since the PWM signals generated by DSP are not appropriate to drive the power MOSFETs, the FET driver circuit is designed to amplify the required PWM level. The lithium-ion cell used in experiment is the H703448-PCM model made by power source energy (PSE) company. Its nominal voltage and capacity is $3.7 \mathrm{~V}$ and $1.25 \mathrm{Ah}$, respectively. Then, the overall system is implemented by one- to-one connection of two lithium-ion cells and two DAB converters, as shown in Fig. 4.

To test the performance to determine the $\mathrm{SOC}_{\text {ref }}^{\text {optimal }}$, the SOCs of each cell are estimated in real-time by (11) based on the ampere-hour counting method with the digital arithmetic operations in DSP. The initial SOC is determined by the measured terminal voltage and SOC relationship provided from the datasheet of H703448-PCM model.

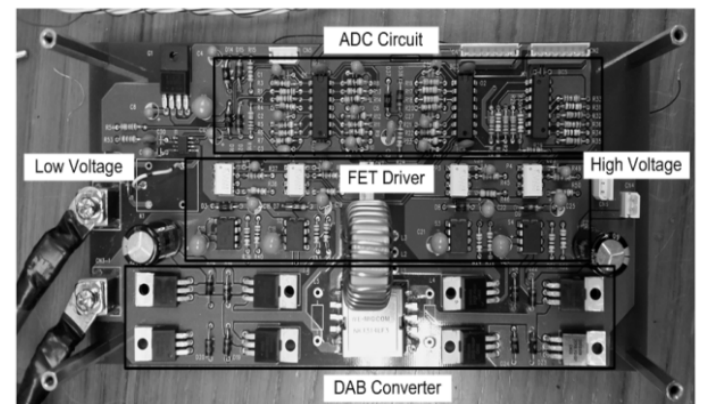

Fig. 10. Hardware implementation of DAB converter

\subsection{Experimental results}

The experimental test is carried out under the same condition as simulation study in Section 4. When the DAB converter operates in a discharge mode, two gate signals to MOSFETs in primary and secondary H-bridges are shown in Fig. 11(a). It is observed that the gate signal $\left(Q_{1}\right)$ in primary H-bridge leads that $\left(Q_{5}\right)$ in secondary H-bridge while resulting in the discharging operation. The value of phase-shift delay, $D$ is 0.2 . Also, the voltages ( $v_{a c 1}$ and $\left.v_{a c 2}\right)$ in both sides of transformer and voltage across inductor $\left(v_{L 1}\right)$ are shown in Fig. 11(b).

When the gate signals $\left(Q_{1}\right.$ and $\left.Q_{5}\right)$ are tuned on, the $v_{a c 1}$ and $v_{a c 2}$ have the positive values, which are $V_{1}$ and $V_{b u s}$, respectively. Moreover, it is known that the response of $v_{L 1}$ is very similar to that by linear combination of $v_{a c 1}$ and $v_{a c 2}$. Note that all experimental results shown in Fig. 11 are almost agreement with theoretical waveforms of DAB converter in a discharging mode given in Fig. 5.

The corresponding responses of battery currents, $i_{b a t 1}$ and $i_{\text {bat } 2}$ and bus voltage, $V_{\text {bus }}$ are shown in Fig. 12. The signs of $i_{\text {bat } 1}$ and $i_{\text {bat } 2}$ are opposite. This means that the DAB converters 1 and 2 in Fig. 4 operate successfully in discharging and charging modes. In addition, all results show that the controllers of each DAB converter perform

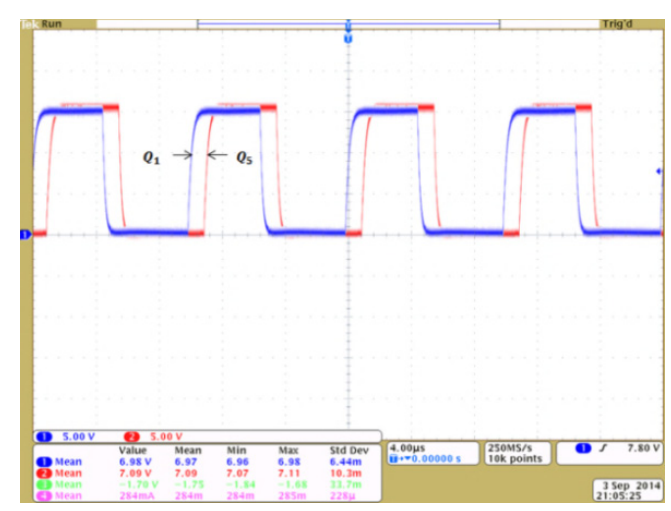

(a)

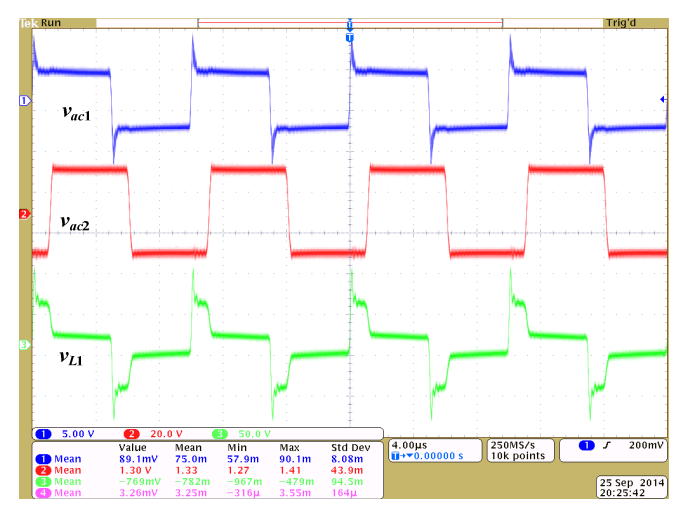

(b)

Fig. 11. Experimental results of DAB converter operation: (a) gate signals to MOSFETs; (b) voltage responses of transformer and inductor 
well when the references are changed for balancing two cells. Note that the experimental results shown in Fig. 12 are almost agreement with simulation results given in Fig. 7 and 8 .

Then, the terminal voltage response during cell balancing by the proposed method is shown in Fig. 13. It is observed that the terminal voltage, $V_{1}$ of (discharged) cell 1 is decreased from 4 to $3.7 \mathrm{~V}$. In contrast, the $V_{2}$ of (charged) cell 2 is increased from 3.5 to $3.7 \mathrm{~V}$, approximately.

Finally, the variations of SOCs by the proposed method are shown in Fig. 14 with the comparison result by the average SOC method. The Fig. 14 is shown the estimated SOCs in real-time by (11) in DSP. The initial SOC reference is 0.65 when the average SOC method is used. It is observed from the result in Fig. 14(a) that cell 2 cannot reach to its SOC reference due to insufficient energy. The SOC difference between two cells after cell balancing is almost $10 \%$. In contrast, when the proposed optimal

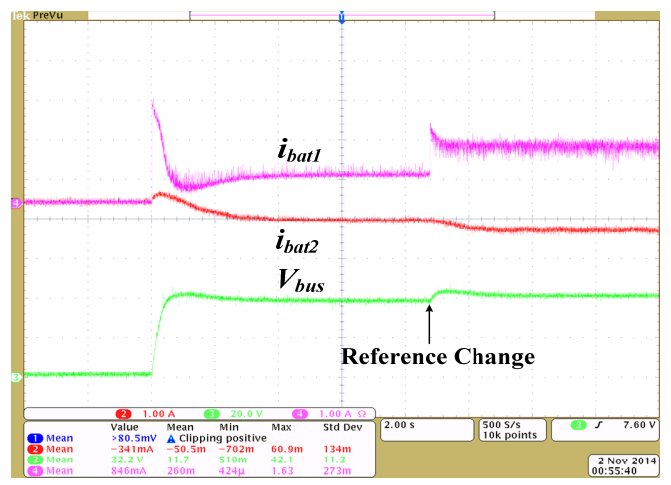

Fig. 12. Reponses of battery currents and bus voltage

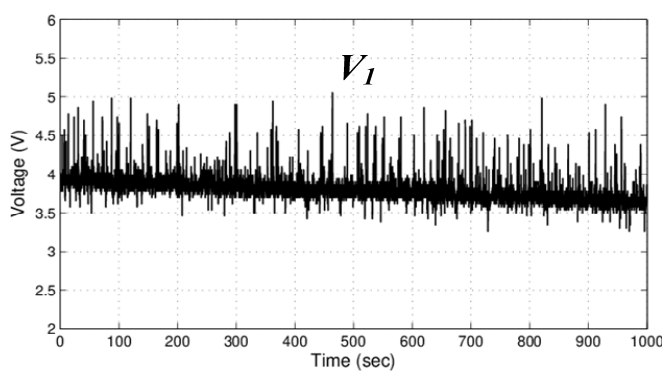

(a)

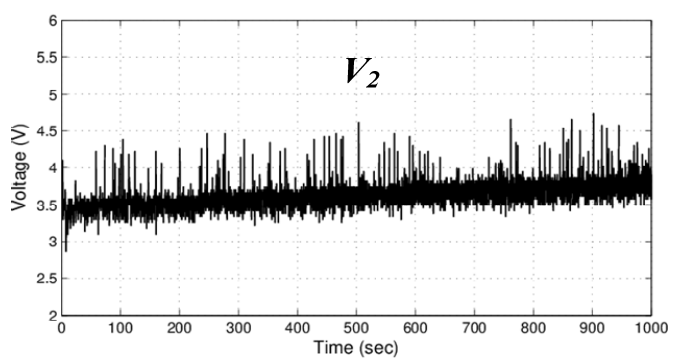

(b)

Fig. 13. Terminal voltages of cells: (a) discharged cell; (b) charged cell

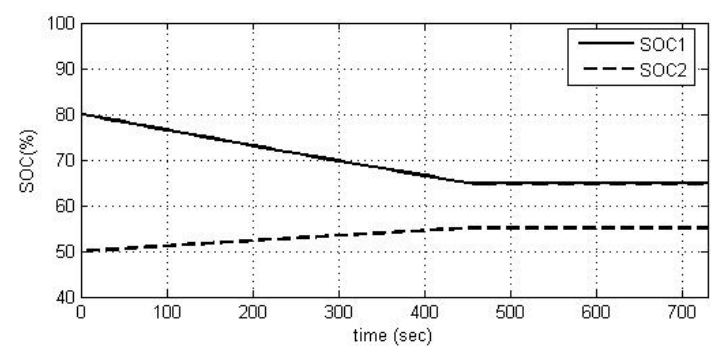

(a)

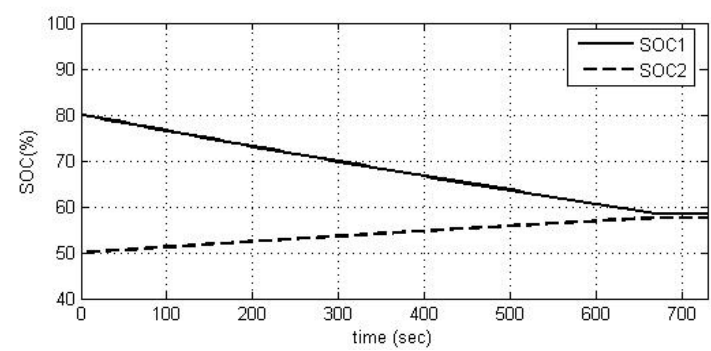

(b)

Fig. 14. Variations of SOCs: (a) by average SOC method; (b) by the proposed active cell balancing method

reference, SOC $_{\text {ref }}^{\text {optimal }}$ by (6) is applied, the result in Fig. 14(b) shows that both cells can reach to the optimal reference of SOC successfully, which is 0.586. Their difference is only $0.1 \%$.

\section{Conclusion}

This paper proposed the new optimal state-of-charge (SOC) reference based active cell balancing method with the dual active bridge (DAB) bidirectional DC/DC converters applied to a common energy bus. In particular, the cell aging and power loss of converters were considered during the energy transfer while determining the optimal reference of SOC. This could improve the real-time energy efficiency and lifespan of battery effectively

Both simulation and experimental tests were carried out to verify the usefulness of proposed method. The results showed that the charging and discharging currents are successfully controlled with the proper phase-shift delay of DAB converters in real-time. Also, it could reduce the SOC difference between multiple cells remarkably when compared to the average SOC method for cell balancing. It is expected that the proposed method could be preferably applied for cell balancing when capacities of multiple cells are very different.

\section{Acknowledgement}

This work was supported by the Power Generation \& Electricity Delivery Core Technology Program of the 
Korea Institute of Energy Technology Evaluation and Planning (KETEP) granted financial resource from the Ministry of Trade, Industry \& Energy, Korea (No. 20131020400920 and No. 20141020402340).

\section{References}

[1] Yuang-Shung Lee and Ming-Wang Cheng, "Intelligent control battery equalization for series connected lithium-ion battery strings," IEEE Trans. Ind. Electron., vol. 52, no. 5, pp. 1297-1307, Oct. 2005.

[2] G. Pellegrino, E. Armando, and P. Guglielmi, "An integral battery charger with power factor correction for electric scooter," IEEE Trans. Power Electron., vol. 25, no. 3, pp. 751-759, Mar. 2010.

[3] S. Yarlagadda, T. T. Hartley, and I. Husain, "A battery management system using an active charge equalization technique based on a DC/DC converter topology," in Proc. IEEE Appl. Power Electron. Conf., pp. 1188-1195, Sep. 2011.

[4] H. Rahimi-Eichi, U. Ojha, F. Baronti, and M. Chow, "Battery management system: An overview of its application in the smart grid and electric vehicles," IEEE Ind. Electron. Mag., vol. 7, no. 2, pp. 4-16, Jun. 2013.

[5] H. S. Park, C. E. Kim, C. H. Kim, G. W. Moon, and J. H. Lee, "A modularized charge equalizer for an HEV lithium-ion battery string," IEEE Trans. Ind. Electron., vol. 56, no. 5, pp. 1464-1476, May 2009.

[6] Y.-S. Lee and G.-T. Cheng, "Quasi-resonant zerocurrent-switching bidirectional converter for battery equalization applications," IEEE Trans. Power Electron., vol. 21, no. 5, pp. 1213-1224, Sep. 2006.

[7] M.-Y. Kim, C.-H. Kim, J.-H. Kim, and G.-W. Moon, "A chain structure of switched capacitor for improved cell balancing speed of lithium-ion batteries," IEEE Trans. Ind. Electron., vol. 61, pp. 3989-3999, Aug 2014.

[8] M. Uno and K. Tanaka, "Single-switch multi-output charger using voltage multiplier for series-connected lithium-ion battery/supercapacitor equalization," IEEE Trans. Ind. Electron., vol. 59, no. 1, pp. 1-12, Jan. 2012.

[9] Y. Yuanmao, K. W. E. Cheng, and Y. P. B. Yeung, "Zero-current switching switched-capacitor zerovoltage-gap automatic equalization system for series battery string," IEEE Trans. Power Electron., vol. 27, no. 7, pp. 3234-3242, Jul. 2012.

[10] X. Wei and B. Zhu, "The research of vehicle power Li-ion battery pack balancing method," in Proc. 9th IEEE Int. Conf. Electron. Meas. Instrum., pp. 24982502, Aug. 2009.

[11] D. Jung, Y. Kim, S. Kim, and S. Lee, "Development of ultracapacitor modules for $42-\mathrm{V}$ automotive electrical systems," J. Power Sources, vol. 114, no. 2, pp. 366-373, Mar. 12, 2003.

[12] M. Einhorn, W. Guertlschmid, T. Blochberger, R. Kumpusch, R. Permann, F. Conte, C. Kral, and J. Fleig, "A current equalization method for serially connected battery cells using a single power converter for each cell," IEEE Trans. Veh. Technol., vol. 60, no. 9, pp. 4227-4237, Nov. 2011.

[13] N. H. Kutkut and D. M. Divan, "Dynamic equalization techniques for series battery stacks," in Proc. 18th Int. Telecommun. Energy Conf., pp. 514-521, 1996,.

[14] C. Pascual and P. Krein, "Switched capacitor system for automatic series battery equalization," in Proc. Modern Tech. Technol., pp. 57-59, 2000.

[15] C. S. Moo, Y. C. Hsieh, and I. S. Tsai, "Charge equalization for series connected batteries," IEEE Trans. Aerosp. Electron. Syst., vol. 39, no. 2, pp. 704710, Apr. 2003.

[16] A. M. Imtiaz and F. H. Khan, "Time shared flyback converter' based regenerative cell balancing technique for series connected Li-ion battery strings," IEEE Trans. Power Electron., vol. 28, no. 12, pp. 59605975, Dec. 2013

[17] M. Tang and T. Stuart, "Selective buck-boost equalizer for series battery packs," IEEE Trans. Aerosp. Electron. Syst., vol. 36, no. 1, pp. 201-211, Jan. 2000.

[18] P. A. Cassani and S. S. Williamson, "Design, testing, and validation of a simplified control scheme for a novel plug-ion hybrid electric vehicle battery cell equalizer," IEEE Trans. Ind. Electron., vol. 57, no. 12, pp. 3956-3962, Dec. 2010.

[19] A. Xu, S. Xie, and X. Liu, "Dynamic voltage equalization for series connected ultracapacitors in EV/HEV applications," IEEE Trans. Veh. Technol., vol. 58, no. 8, pp. 3981-3987, Oct. 2009.

[20] M. Einhorn, W. Roessler, and J. Fleig, "Improved performance of serially connected Li-ion batteries with active cell balancing in electric vehicles," IEEE Trans. Veh. Technol., vol. 60, no. 6, pp. 2448-2457, Jul. 2011.

[21] X. Lu, K. Sun, J. M. Guerrero, J. C. Vasquez, and L. Huang, "State-of- charge balance using adaptive droop control for distributed energy storage systems in DC microgrid applications," IEEE Trans. Ind. Electron., vol. 61, no. 6, pp. 2804-2815, Jun. 2014.

[22] J. Kim, J. Shin, C. Chun, and B. H. Cho, "Stable configuration of a Li-ion series battery pack based on a screening process for improved voltage/SOC balancing," IEEE Trans. Power Electron., vol. 27, no. 1, pp. 411-424, Jan.2012.

[23] L. Maharjan, S. Inoue, H. Akagi, and J. Asakura, "State-of-Charge(SOC)-balancing control of a battery energy storage system based on a cascade PWM converter," IEEE Trans. Power Electron., vol. 24, no. 6, pp. 1628-1636, Jun. 2009.

[24] M. Shahriari and M. Farrokhi, “Online state-of-health 
estimation of VRLA batteries using state of charge," IEEE Trans. Ind. Electron., vol. 60, no. 1, pp. 191202, Jan. 2013.

[25] H. Wen, W. Xiao, and B. Su. "Nonactive power losses minimization in a bidirectional isolated DCDC converter for distributed power system," IEEE Trans. Ind. Electron., vol. 61, no. 12, pp. 6822-6831, Dec. 2014.

[26] Y. Xie, J. Sun, and J. S. Freudenberg, "Power flow characterization of a bidirectional galvanically isolated high-power DC/DC converter over a wide operating range," IEEE Trans. Power Electron., vol. 25, no. 1, pp. 54-66, Jan. 2010.

[27] B. Zhao, Q. Yu, and W. Sun, "Extended-phase-shift control of isolated bidirectional dc-dc converter for power distribution in microgrid," IEEE Trans. Power Electron., vol. 27, no. 11, pp. 4667-4680, Nov. 2012.

[28] C. Mi, H. Bai, C. Wang, and S. Gargies, "The operation, design, and control of dual h-bridge based isolated bidirectional DC-DC converter," IET Power Electron., vol. 1, no. 3, pp. 176-187, Jan.2008.

[29] M. Gholizadeh and F. R. Salmasi, "Estimation of state of charge, unknown nonlinearities, state of health of a lithium-ion battery based on a comprehensive unobservable model," IEEE Trans. Ind. Electron., vol. 61, no. 3, pp. 1335-1344, Mar. 2014.

[30] D. V. Do, C. Forgez, K. El Kadri Benkara, and G. Friedrich, "Impedance observer for a Li-ion battery using Kalman filter," IEEE Trans. Veh. Technol., vol. 58, no. 8, pp. 3930-3937, Oct. 2009.

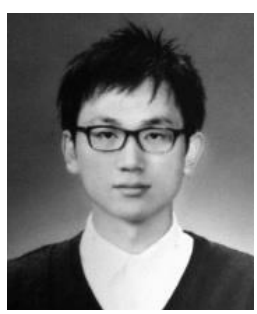

SunHo Bae received the B.S. degree from the Department of Mechanical and Control Engineering, Handong University, Pohang, Korea, in 2010. He is currently working toward the Ph.D. degree in a combined M.S. and Ph.D. program at Yonsei University, Seoul, Korea. His research interests include power control of electric vehicle, hardware implementation of grid-connected inverter with photovoltaic and energy storage devices, and energy management system for optimization of hybrid energy storage systems.

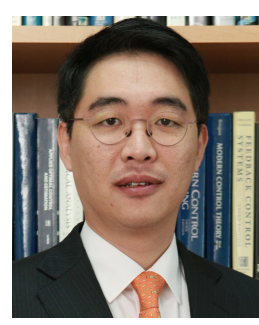

Jung-Wook Park received the B.S. degree (summa cum laude) from the Department of Electrical Engineering, Yonsei University, Seoul, Korea, in 1999, and the M.S.E.C.E. and Ph.D. degrees from the School of Electrical and Computer Engineering, Georgia Institute of Technology, Atlanta, USA in 2000 and 2003, respectively. He was a Post-doctoral
Research Associate in the Department of Electrical and Computer Engineering, University of Wisconsin, Madison, USA during 2003 2004. He is currently a professor in the School of Electrical and Electronic Engineering, Yonsei University, Seoul, Korea. He is now leading the National Leading Research Laboratory (NLRL) designated by Korea government to the subject of integrated optimal operation for smart grid. His current research interests are in power system dynamics, renewable energies based distributed generations, power control of electric vehicle, and optimization control algorithms. Prof. Park was the recipient of the Young Scientist Presidential Award in 2013 from the Korean Academy of Science and Technology (KAST), Korea.

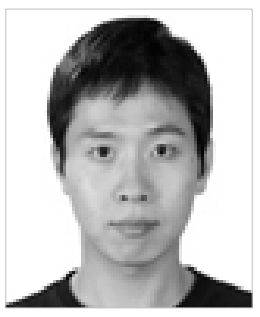

Soo Hyoung Lee received the B.S. and $\mathrm{Ph} . \mathrm{D}$. degrees of electrical engineering from the School of Electrical and Electronic Engineering, Yonsei University, Seoul, Korea, in 2008 and 2012, respectively. He was a Post-doctoral Research Associate in the School of Electrical and Computer Engineering, Georgia Institute of Technology, Atlanta, GA, USA during 2012 2014. He is currently a Senior Researcher in the Advanced Power Grid Research Division, Korea Electrotechnology Research Institute (KERI). He was the recipient of the Gold Prize Paper Award from the TMS (Telecommunication, Multimedia, and SOC) Institute of Technology and Second Prize Paper Award from the Yonsei Electric Power Research Center. His research interests are converter based microgrid, optimal coordination of distributed generation systems, converter control for distributed generation systems, and implementation of multi-level converters. 